\title{
A Single Sensisitizer for the Excitation of Visible and NIR Lanthanide Emitters (Sm, Eu, Tb, Dy and Ho) in Water with High Quantum Yields
}

\author{
Ga-Lai Law, Tiffany A. Pham, Jide Xu, and Kenneth N. Raymond ${ }^{\star}$ \\ Department of Chemistry, University of California Berkeley, Berkeley, CA, 94720-1460 (USA)
}

\section{Abstract}

The versatile octadentate TIAM ligand forms lanthanide ( $\mathrm{Sm}, \mathrm{Eu}, \mathrm{Tb}, \mathrm{Dy}, \mathrm{Ho}$ ) complexes with high quantum yields in water. This ligand is an efficient sensitizer, and also shields the metal center from solvent quenching, as shown by an X-ray diffraction study of the Ho complex.

\section{Keywords}

holmium; lanthanide sensitization; octadentate ligand; Vis NIR emitter; X-ray diffraction

In recent years the use of lanthanides luminescence for biological applications has been of increasing importance. ${ }^{[1]}$ The development of such luminescent compounds has been due to the burgeoning demand for multifunctional and efficient luminescent markers to probe signal transduction, neurobiology, cancer, stem cell biology, and infectious diseases. ${ }^{[2]}$ This has initiated a recent focus on multiplexing assays, for which the multifunctional design is still problematic. Approaches using nanoparticles and quantum dots, ${ }^{[3]}$ have been somewhat successful, but the limitations of these materials are still problematic. ${ }^{[4]}$

Herein we report a versatile, multidentate ligand that has been found to sensitize both visible and near-infrared (NIR) emitters by using the same excitation wavelength, with significantly high quantum yields. This has been a persistent challenge, as different lanthanides have different emitting states that are easily quenched by nonradiative decay processes. ${ }^{[5]} \mathrm{We}$ have previously described the properties of several emissive terbium complexes with high quantum yields that feature the 2-hydroxyisophthalamide binding unit (IAM) ${ }^{[6,7]}$ Past studies have shown that similar tetradentate and octadentate ligands ${ }^{[7]}$ form $\mathrm{Tb}^{\mathrm{III}}$ complexes with comparable photophysical properties. We ascribe this to the fact that modifying the functional groups of the sensitizer does not play a major role in changing the electron distribution of the ligand chromophore and its chelating oxygen atoms, based on investigation of different electron-withdrawing and donating groups on the para position of the chromophore's aromatic ring. Using TD-DFT calculations and screening studies with tetradentate ligands, ${ }^{[8]}$ the inclusion of an additional amide group on the para position of the ring was thought to be favorable to the electronics of the system. It is further hypothesized that large molecular appendages will result in better shielding of the metal center. The TIAM binding moiety was introduced in the ligand design to investigate both of these hypotheses.

*Fax: (+1) 510-486-5283 raymond@ socrates.berkeley.edu.

Supporting information for this article is available on the WWW under http://www.angewandte.org or from the author. 
The octadentate ligand $\left(\mathbf{L H}_{4}\right)$ has four TIAM chromophores attached to an $\mathrm{H}(2,2)$ backbone (Fig. 1a), and has been found to sensitize a range of visible emitters: $\mathrm{Sm}, \mathrm{Eu}, \mathrm{Tb}, \mathrm{Dy}$, as well as Ho, which emits in both the visible and NIR regions. The sensitization of the metal occurs through the ligand, which is simultaneously the chromophore and chelator. ${ }^{[9]}$ These emitters display uncommonly high luminescent properties in water, given that they are extremely sensitive to $\mathrm{O}-\mathrm{H}$ vibronic quenching.

The $\left[\mathrm{Ln}^{\mathrm{III}} \mathbf{L}\right]^{-}$complexes $(\mathrm{Ln}=\mathrm{Sm}, \mathrm{Eu}, \mathrm{Tb}, \mathrm{Dy}, \mathrm{Ho})$ were characterized by the crystal structure of the holmium complex (Fig. 1b) and by HT-ESI mass spectrometry. The synthesis and Characterization data is shown in the SI and the experimental section.

In general, emission from holmium complexes is rare, especially in the solution state, since their electronic structure is susceptible to nonradiative deactivation. There have been fewer than ten reports on holmium complexes with documented solution state luminescence and photophysics to date. ${ }^{[11]}$ We show here the emission spectra of Ho in water with emission in both the visible and NIR regions (Fig. 2). The observed peaks are assigned at $\sim 640 \mathrm{~nm}, 990$ $\mathrm{nm}$ with a slight shoulder at $1010 \mathrm{~nm}$ (the most prominent band), and the weaker transitions are observed at 1210 and $1450 \mathrm{~nm}$, which correspond to the transition bands of ${ }^{5} \mathrm{~F}_{5}$ $\rightarrow{ }^{5} \mathrm{I}_{8},{ }^{5} \mathrm{~F}_{5} \rightarrow{ }^{5} \mathrm{I}_{7},{ }^{5} \mathrm{I}_{6} \rightarrow{ }^{5} \mathrm{I}_{8}$, and ${ }^{5} \mathrm{~F}_{5} \rightarrow{ }^{5} \mathrm{I}_{6}$, respectively. These bands are observed due to the relaxation of the photons from the multiple upper $4 \mathrm{f}$ levels to the ${ }^{5} \mathrm{~F}_{5}$, and ${ }^{5} \mathrm{I}_{6}$ first excited states of the $\mathrm{Ho}^{3+}$ ion before decaying to the ${ }^{5} \mathrm{I}_{6},{ }^{5} \mathrm{I}_{7},{ }^{5} \mathrm{I}_{8}$ (Fig. 2). This is the first time that the weak transition bands at 1210 and $1450 \mathrm{~nm}$ have been reported in aqueous solution. In most cases, these bands are not observed due to strong reabsorption of the weakly emitted NIR radiation by the solvent, which has an absorption coefficient of nearly two orders of magnitude higher than the Ho transitions. ${ }^{[12]}$

The only measurable lifetime was at $1010 \mathrm{~nm}$ and gave an monoexponential curve $\left(\tau_{\mathrm{obs}}=\right.$ $11 \mathrm{~ns}$ ) (Table 1). In aqueous solution the other transition bands were too weak to give conclusive values, however, aqueous emission spectra, quantum yields and lifetimes have been collected for the other four visible emitters, SmL, EuL, TbL and DyL (Table 2). The emission spectra with their assigned f-f transitions are shown in Figure 3.

The Sm ${ }^{\mathrm{III}}$ complex produced four characteristic bands, peaking at 562.5, 605.0, 650.0 and $710.0 \mathrm{~nm}$, which are responsible for the transitions from the emitting ${ }^{4} \mathrm{G}_{5 / 2}$ state to the ${ }^{6} \mathrm{H}_{\mathrm{J}}(\mathrm{J}$ $=5 / 2,7 / 2,9 / 2$ and 11/2, respectively). For DyL, the characteristic bands associated with the emitting ${ }^{4} \mathrm{~F}_{9 / 2}$ state of Dy III were observed at 481.0, 575.6, 664.1 and $752.5 \mathrm{~nm}$, where the hypersensitive ${ }^{5} \mathrm{~F}_{9 / 2} \rightarrow{ }^{6} \mathrm{H}_{13 / 2}$ is the most dominant. For EuL and TbL, these were the two most emissive complexes as expected as they have fewer excited states and ground states in contrast to $\mathrm{Sm}$ and $\mathrm{Dy}$. $\mathrm{Tb} \mathbf{L}$ was the most luminescent giving the highest quantum yield $(\Phi$ $\sim 47 \%$ ) For EuL, it should be noted that from the spectra, the ratio of the ${ }^{7} \mathrm{~F}_{4}$ transition of the europium is unusually high relative to the ${ }^{7} \mathrm{~F}_{2}$ transition. This is uncommonly observed for europium but has been previously reported, ${ }^{[13]}$ and can be an attributing factor for the low quantum yield obtained as it indicates a different coordination geometry. Another possible cause of the quenching could be by electron transfer processes.

The triplet state of the Gd complex was observed from studies at $77 \mathrm{~K}$ at $23148 \mathrm{~cm}^{-1}$, which is masked at room temperature. This is shown by the predominant ligand fluorescence of the complexes, centered around $432 \mathrm{~nm}$ in water (SI Fig. 3), which also indicates inefficient energy transfer. Microsecond lifetimes (58 $\mu$ s) confirm the phosphorescence observed which is promoted by the heavy metal effect of the Gd. ${ }^{[14]}$ The high emitting states of the Gd $\left({ }^{6} \mathrm{P}_{7 / 2}\right)$ prevent energy transfer to the metal ion. The general energy transfer mechanism of these complexes involves population of the ligand singlet state followed by intersystem crossing to the triplet state and finally to the nearest excited states of the metal. 
These complexes all show relatively high quantum yields in water with extinction coefficients of $\sim 23000 \mathrm{M}^{-1} \mathrm{~cm}^{-1}$. The quantum yield of $\mathrm{Tb}$ is around $47 \%$, while Eu was poorly sensitized relative to higher values cited in the literature; however, its quantum yield is still higher than that of the commercially used Eu cryptand assay of 2\%. ${ }^{[15]}$ Thus, all these complexes show potential for multiplexing applications, as they can all be excited with the same wavelength. The lifetimes are relatively long, and from both Horrocks' and Parker's corrected $q$ equations, ${ }^{[16]}$ the calculated $q$ value is approximately zero, which suggests that there are no coordinating water molecules in the inner sphere. This is also supported by the crystal structure of HoL.

From the photophysical measurements it can be concluded that the triplet state of the ligand alone cannot account for the remarkable luminescence properties, as all five lanthanide emitters have different excited states. The energy differences between the triplet level of the ligand and the lowest emitting states of the five different lanthanides account for the different sensitization efficiencies. For example, with Tb complexes, it is well known that an energy gap of $3500 \mathrm{~cm}^{-1}$ or higher is necessary to facilitate efficient and irreversible energy transfer. ${ }^{[17]}$ Here the energy gap is much smaller $\left(\sim 2659 \mathrm{~cm}^{-1}\right)$ whereas for EuL the gap of $\sim 5909 \mathrm{~cm}^{-1}$ is much greater than the ideal $\sim 1800 \mathrm{~cm}^{-1}$ a prerequisite to prevent back energy transfer. For the europium system, the high triplet of the ligand can facilitate relaxation to the ${ }^{5} \mathrm{D}_{2}$ transition $\left(21500 \mathrm{~cm}^{-1}\right)$ instead of to the ${ }^{5} \mathrm{D}_{1}$.

We believe that in addition to the well-matched triplet state, the strong luminescent properties were attributed to the coordination geometry and the protruding amide groups on the exterior of the ligand that limit solvent access to the metal center. These factors contribute to the reduction in nonradiative decay processes, which is especially important for lanthanides with numerous closely emitting states and hypersensitive transitions. The crystal structure of the holmium complex supports this hypothesis, as the metal center is well encapsulated by the ligand, while the para amide groups extend from the complex acting like a secondary shield from solvent molecules.

Rhomboid single crystals suitable for X-ray diffraction of $\mathrm{HoL}$ as the pyridinium salt were grown by layering diethyl ether onto a 5\% aqueous DMF/MeOH 1:1 (v/v) solution of the complex. The HoL complex spontaneously resolves to crystallize in the chiral orthorhombic space group $C 222_{1}$ (Fig. 1b). ${ }^{[10]}$ The crystallographic data (Table S1) and selected bond distances and angles (Table S2) are in the supporting information. Interestingly, the holmium atoms are not equivalent and do not lie on the eight general positions of this space group, but rather on two different special positions with $C_{2}$ symmetry axes. The unit cell is comprised of two $[\mathrm{HoL}]^{-}$complexes (with metal centers denoted as Ho1 and Ho2) with a coordination number of eight (Fig. 4a) and significantly different coordination environments (Fig. 4b,4c).

The three most common polyhedra describing the coordination geometry for an eightcoordinate complex are the bicapped trigonal prism $\left(C_{2 V}\right)$, square antiprism $\left(D_{4 d}\right)$, and trigonal dodecahedron $\left(D_{2 d}\right)$. The shape measure $(\mathrm{SM})$ parameter is a reference to the agreement between these idealized polyhedra and the observed structure. ${ }^{[18]}$ Shape analysis of the coordination environment around Hol reveals that it is best described as a dodecahedron $\left(\mathrm{SM}=7.04\left(D_{2 d}\right), 11.96\left(C_{2 V}\right)\right.$, and $\left.15.64\left(D_{4 d}\right)\right)$, while Ho2 is closest to a square antiprism $\left(\mathrm{SM}=7.47\left(D_{4 d}\right), 8.34\left(D_{2 d}\right)\right.$, and $\left.10.19\left(C_{2 v}\right)\right)(\mathrm{Fig} .4 \mathrm{~b}, 4 \mathrm{c})$, similar to several other eight-coordinate holmium complexes. ${ }^{[11 \mathrm{c}, 19]}$ Both structures are intermediate between the ideal $D_{2 d}$ and $D_{4 d}$ geometries, with similarly seen $D_{2}$ symmetry in each case. For Ho1 the bidentate ligands are twisted off the $\mathrm{D}_{2 d}$ mirror planes, while for Ho2 the top and bottom faces of the antiprism are rectangular rather than square. 
The TIAMs alternate in binding through the amide carbonyl connected to the backbone and the pendant one. As expected, the average length of the (hydroxyl) O-Ho bond is significantly smaller than that of the (keto) O-Ho bond--2.30 A vs. $2.38 \AA$. The aromatic rings pendant from the same side of the bridge engage in notable $\pi$-stacking, while hydrogen bonding is observed between the amide protons and the coordinating hydroxyl oxygens. These interactions most likely contribute to the stability of the complex.

In conclusion, we have reported a new holmium luminescent complex and its emission spectra in both the visible and NIR region. This work shows that the incorporation of external groups on the ligand can form a secondary shield to reduce external quenching effects and thus is a significant factor to consider in ligand design. An unmet need in the field of biological imaging applications is for multiplex assays using a single excitation source. The $\mathrm{H}(2,2)$ TIAM ligand offers a promising approach, as it forms highly emissive complexes in water with a variety of lanthanides.

\section{Experimental Section}

All chemicals and solvents were used without further purification unless otherwise stated. The $\mathrm{Ln}^{\mathrm{III}}$ salts utilized were of the highest possible purity (>99.99\% or $(>99.999 \%)$. The synthesis of $\mathbf{L H}_{4}$ is shown in the supporting information. Mass spectra were obtained by the QB3/Chemistry Mass Spectrometry Facility at the University of California, Berkeley, CA.

X-ray diffraction data collection was performed at the X-Ray Facility in the College of Chemistry at the University of California, Berkeley, using protocols detailed in the SI. Resulting drawings of molecules were produced with ORTEP-3 for Windows. ${ }^{[20]}$ CCDC 797480 contains the supplementary crystallographic data for this paper. These data can be obtained free of charge from The Cambridge Crystallographic Data Centre via www.ccdc.cam.ac.uk/data_request/cif.

\section{Supplementary Material}

Refer to Web version on PubMed Central for supplementary material.

\section{Acknowledgments}

The lanthanide luminescence research is supported by the Director, Office of Science, Office of Basic Energy Sciences, Division of Chemical Sciences, Geosciences, and Biosciences of the U.S. Department of Energy at LBNL under Contract No. DE-AC02-05CH1 1231, and related support is from NIH Grant HL069832 for other aspects of this research.

\section{References}

1. a) Rajapakse HE, Reddy DR, Mohandessi S, Butlin NG, Miller LW. Angew. Chem. 2009; 118:15.Angew. Chem. Int. Ed. 2009; 48:4990-4992.b) Kim SH, Gunther JR, Kalzenellenbogen JA. J. Am. Chem. Soc. 2010; 132:4685-4692. [PubMed: 20230029] c) Moore EG, Samuel APS, Raymond KN. Acc. Chem. Res. 2009; 42:542-552. [PubMed: 19323456]

2. Haas KL, Franz KJ. Chem. Rev. 2009; 109:4921-4960. [PubMed: 19715312]

3. a) Morgner F, Geisler D, Butlin NG, Lohmannsroben H-G, Hidebrandt N. Angew. Chem. Int. Ed. 2010; 49:7570-7574.b) Chen S, Wang L, Duce SL, Brown S, Lee S, Melzer A, Cuschieri A, Andre P. J. Am. Chem. Soc. ASAP.

4. Binnemans K. Chem. Rev. 2009; 109:4283-4374. [PubMed: 19650663]

5. Bünzli J-CG, Chauvin A-S, Kim HK, Deiters E, Eliseeva SV. Coord. Chem. Rev. 2010; 254:26232633. 
6. a) Johansson MK, Cook RM, Xu J, Raymond KN. J. Am. Chem. Soc. 2004; 126:16451-16455. [PubMed: 15600347] b) Petoud S, Cohen SM, Bünzli J-CG, Raymond KN. J. Am. Chem. Soc. 2003; 125:13324-113325. [PubMed: 14583005]

7. a) Samuel APS, Moore EG, Melchior M, Xu J, Raymond KN. Inorg.Chem. 2008; 47:7535-7544. [PubMed: 18671388] b) Samuel APS, Lunkley JL, Muller G, Raymond KN. Eur. J. Inorg. Chem. 2010:3343-3347. [PubMed: 20730030]

8. Samuel APS, Xu J, Raymond KN. Inorg. Chem. 2009; 48:687-698. [PubMed: 19138147]

9. Gorden AEV, Xu J, Raymond KN, Durbin P. Chem. Rev. 2003; 103:4207-4282. [PubMed: 14611263]

10. Crystal data: $\mathrm{C}_{54} \mathrm{H}_{64} \mathrm{~N}_{14} \mathrm{O}_{16} \mathrm{Ho}\left(M_{\mathrm{r}}=1330.12 \mathrm{~g} \mathrm{~mol}^{-1}\right)$, light pink rhomboid, 1.04 x $0.52 \times 0.27$ $\mathrm{mm}$, orthorhombic, space group $C 222_{1}$ (No. 20), $a=17.455(5), b=47.542(13), c=27.414(8) \AA$, $a=90, \beta=90, \gamma=90^{\circ}, V=22750(11) \AA^{3}, Z=8, \rho_{\text {calcd }}=0.777 \mathrm{Mg} / \mathrm{m}^{3}, \mu=0.737 \mathrm{~mm}^{-1}$, Mo X-ray radiation source $\lambda=0.71073 \AA, T=163(2) \mathrm{K}, 293944$ measured reflections, 20707 independent reflections, $R_{1}\left(I>2 \sigma(\mathrm{I})=0.0367, w R_{2}\right.$ (all data) $=0.0930, \mathrm{GOF}=1.079$.

11. a) Quici S, Cavazzini M, Marzanni G, Accorsi G, Armaroli N, Ventura B, Barigelletti F. Inorg. Chem. 2005; 44:529-537. [PubMed: 15679381] b) Zhang J, Badger PD, Geib SJ, Petoud S. Angew. Chem. 2005; 117:2564-2568.Angew. Chem. Int. Ed. 2005; 44:2508-2512.c) Moore EG, Szigethy G, Xu J, Pålsson L-O, Beeby A, Raymond KN. Angew. Chem. 2008; 49:96429645.Angew. Chem. Int. Ed. 2008; 47:9500-9503.

12. Palmer KF, Williams D. J. Opt. Soc. Am. 1974; 64:1107-1110.

13. SáFerreira RA, Nobre SS, Granadeiro CM, Nogueira HIS, Carlos LD, Malta OL. J. Lumin. 2005; 121:561-567.

14. Giachino GG, Kearns DR. J. Chem. Phys. 1970; 52:2964-2974.

15. Alpha B, Lehn J-M, Mathis G. Angew. Chem. 1987; 99:259-256.Angew. Chem. Int. Ed. 1987; 26:6.

16. a) Supkowski RM, Horrocks WdeW Jr. Inorg. Chim. Acta. 2002; 340:44-48.b) Beeby A, Clarkson IM, Dickins RS, Faulkner S, Parker D, Royle 1, De Sousa AS, Williams JAG, Woods M. J. Chem. Soc. Perkin Trans. 1999; 2:493-502.c) Hakala H, Litti P, Peuralahti J, Karvinen J, Mukkala V-M, Hovinen J. J. Lumin. 2005; 113:17-26.

17. Steemers FJ, Verboom, W W, Reinhoudt DN, Van der Tol EB, Verhoeven JW. J. Am. Chem. Soc. 1995; 117:9408-9414.

18. a) Xu J, Radkov E, Ziegler M, Raymond KN. Inorg. Chem. 2000; 39:4156-4164. [PubMed: 11198875] b) Kepert DL. Prog. Inorg. Chem. 1978; 24:179-249.

19. a) Gonzales-Lorenzo M, Platas-Iglesias C, Avecilla F, Faulkner S, Pope SJA, de Blas A, Rodriguez-Blas T. Inorg. Chem. 2005; 44:4254-4262. [PubMed: 15934753] b) Miranda P Jr, Sukerman-Schpector J, Isolani PC, Vicentini G, Zinner LB. J. Alloys Compd. 2001; 323-324:1317.

20. ORTEP-3 for Windows: Farrugia LJ. J. Appl. Crystallogr. 1997; 30:565. 
a)<smiles>[R]CCN(CC[R])CCN(CC[R])CC[R]</smiles>

b)

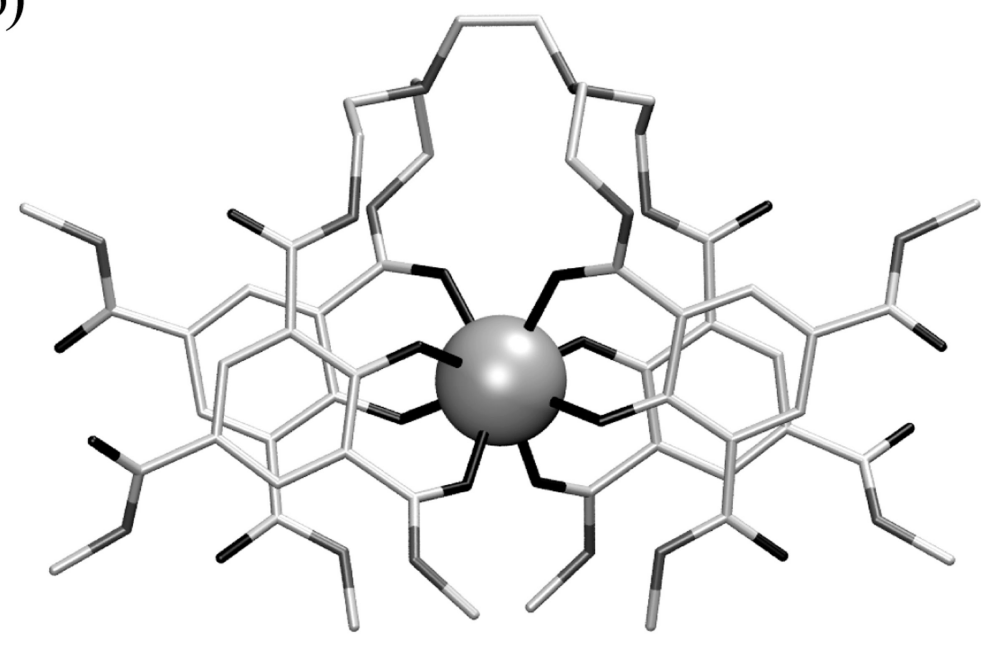

Figure 1.

a) Chemical structure of the $\mathrm{H}(2,2)$ (above) scaffold and the TIAM (below) binding moiety in $\mathrm{LH}_{4}$. b) View of the X-ray crystal structure of [HoL] $]^{-}$(gray C, red O, blue N, orange Ho). 


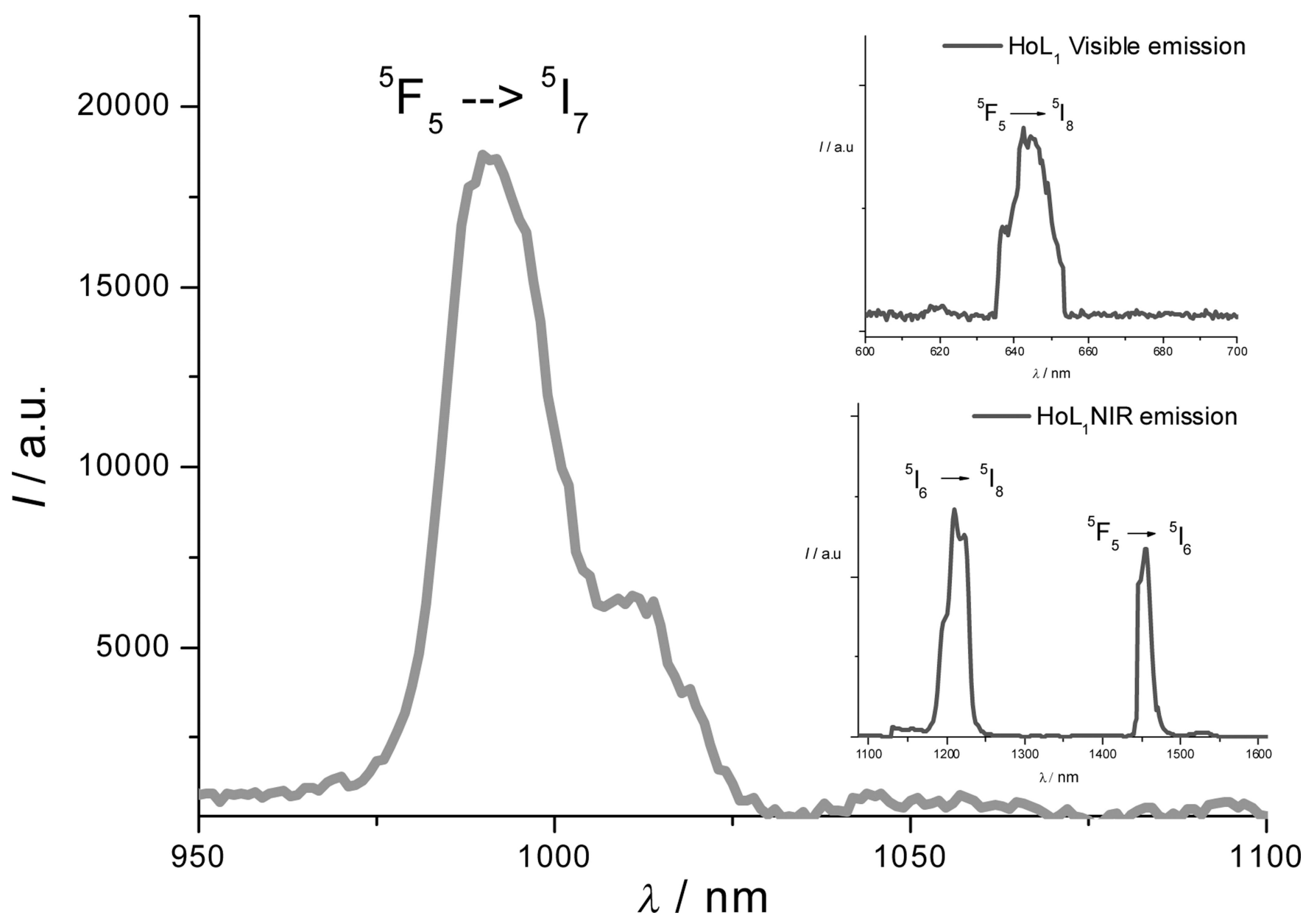

Figure 2.

HoL emission spectra in water and (<5\%DMSO) at $\lambda_{\text {exc }}=330 \mathrm{~nm}$. Strongest emission in NIR at $940 / 1010 \mathrm{~nm}$, Inset a) ${ }^{5} \mathrm{~F}_{5} \rightarrow{ }_{-}^{5} \mathrm{I}_{8}$, very weak emission in the visible region at 640 $\mathrm{nm}$ and b) the ${ }^{5} \mathrm{I}_{6} \rightarrow{ }_{-}^{5} \mathrm{I}_{8}$ and ${ }^{5} \mathrm{~F}_{5} \rightarrow-{ }^{5} \mathrm{I}_{8}$ transitions bands at 1210 and $1455 \mathrm{~nm}$ in the NIR region. 

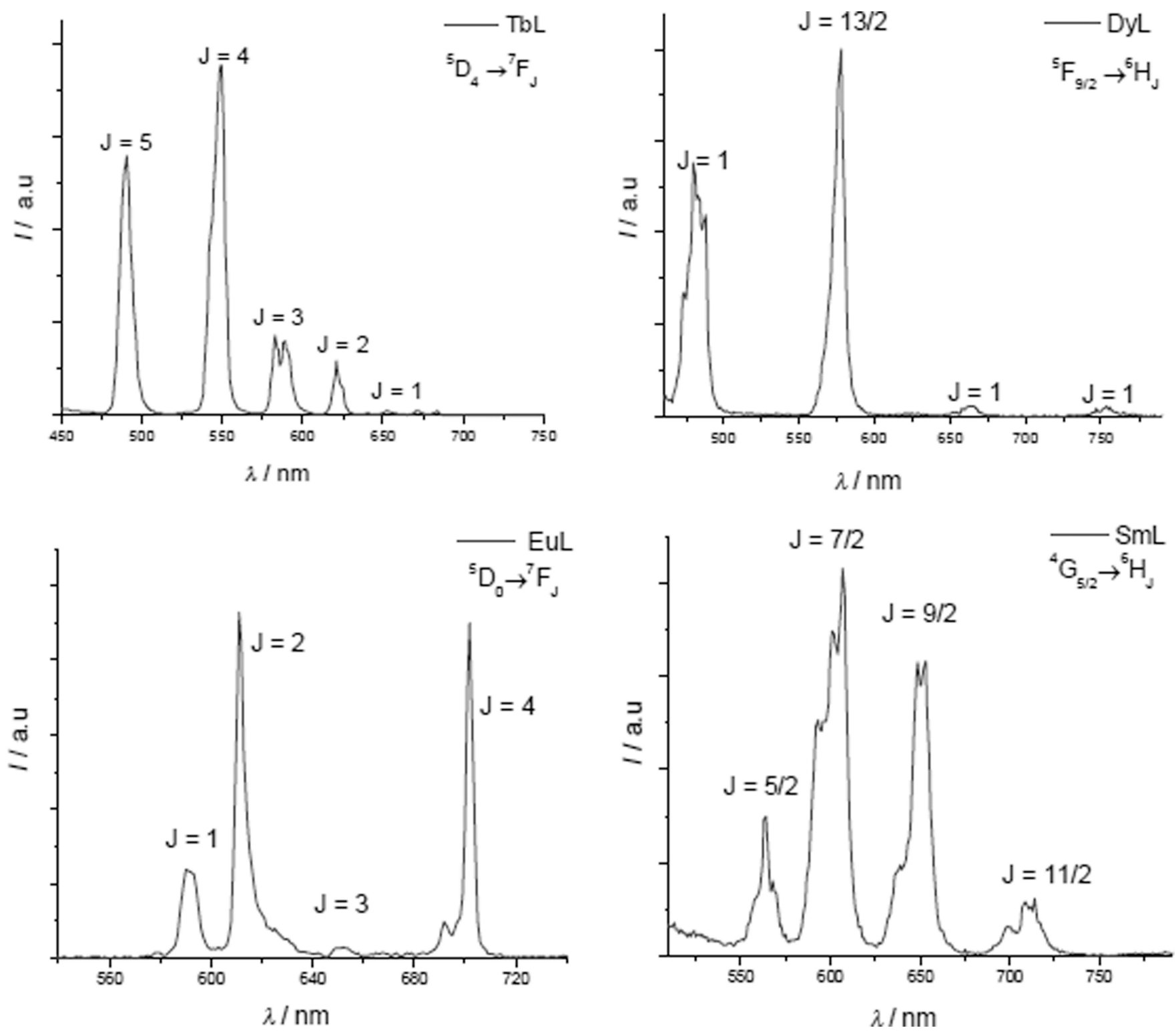

Figure 3.

Room temperature emission spectra of a) Tb $\mathbf{L}$ b) Dy $\mathbf{L}$, c) EuL, d) Sm $\mathbf{L}$ at $\lambda_{\text {exc }}=350 \mathrm{~nm}$ in water with $<5 \%$ DMSO. 
a)

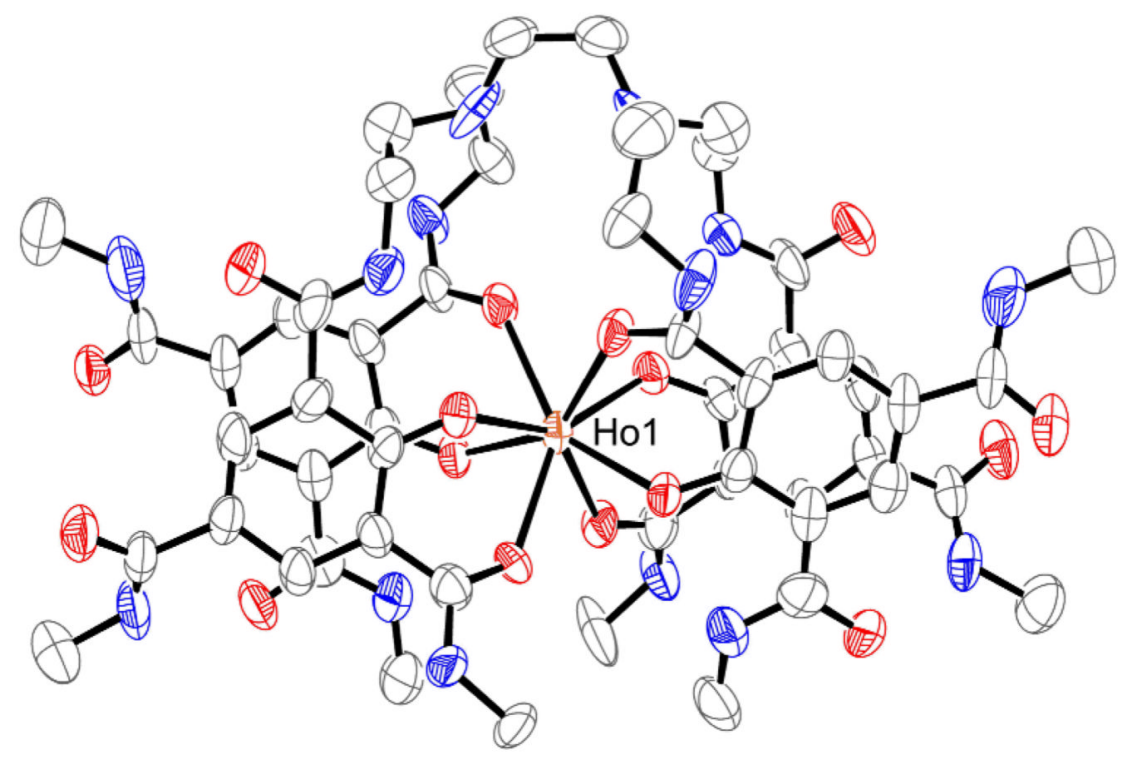

b)
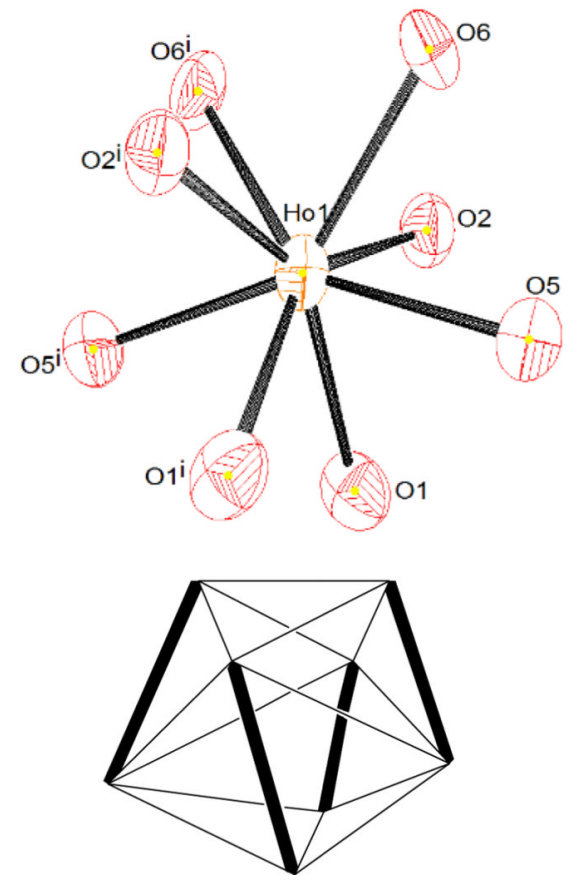

c)
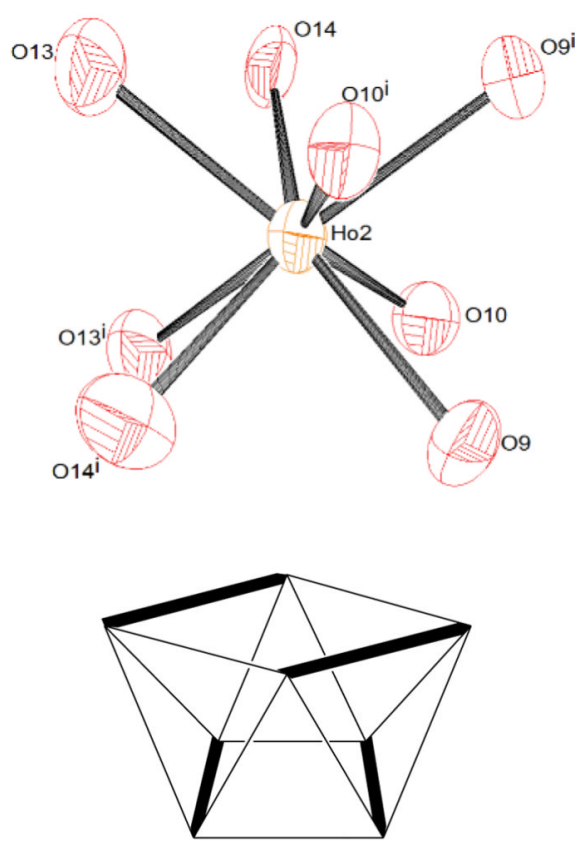

Figure 4.

(a) ORTEP diagram of the X-ray crystal structure of the Hol anionic complex. Thermal ellipsoids are drawn at the $50 \%$ probability level. Inner coordination environments of the Ho1 (b) and Ho2 (b) cations. The bold edges of the corresponding idealized polyhedra are those spanned by the binding moieties. 


\section{Table 1}

Photophysical data of HoL in water.

\begin{tabular}{|llll|}
\hline HoL & transitions & $\begin{array}{l}\boldsymbol{\lambda}_{\text {em }}(\mathbf{m a x}) \\
\mathbf{n m}\end{array}$ & $\boldsymbol{\tau}_{\mathbf{H 2 O}}$ \\
\hline & ${ }^{5} \mathrm{~F}_{5} \rightarrow-{ }^{5} \mathrm{I}_{8}$ & $\sim 645$ & $/$ \\
& ${ }^{5} \mathrm{~F}_{5} \rightarrow-{ }^{5} \mathrm{I}_{7}$ & $990 / 1010$ & $11 \mathrm{~ns}$ \\
& ${ }^{5} \mathrm{I}_{6} \rightarrow-{ }_{-} \mathrm{I}_{8}$ & 1210 & $/$ \\
& ${ }^{5} \mathrm{~F}_{5} \rightarrow-{ }^{5} \mathrm{I}_{8}$ & 1450 & $/$ \\
$\mathbf{L}$ (fluorescence) & $\mathrm{S}_{1} \rightarrow \mathrm{S}_{0}$ & 407 & $48 \mathrm{~ns}$ \\
$\mathbf{L}$ (phosphorescence) & $\mathrm{T}_{1} \rightarrow \mathrm{S}_{0}$ & 432 & $58 \mu \mathrm{s}$ \\
\hline
\end{tabular}




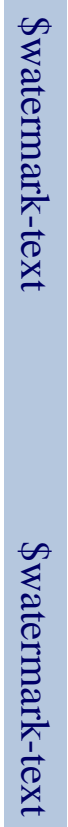

$N$
$\frac{0}{0}$
$\frac{0}{10}$

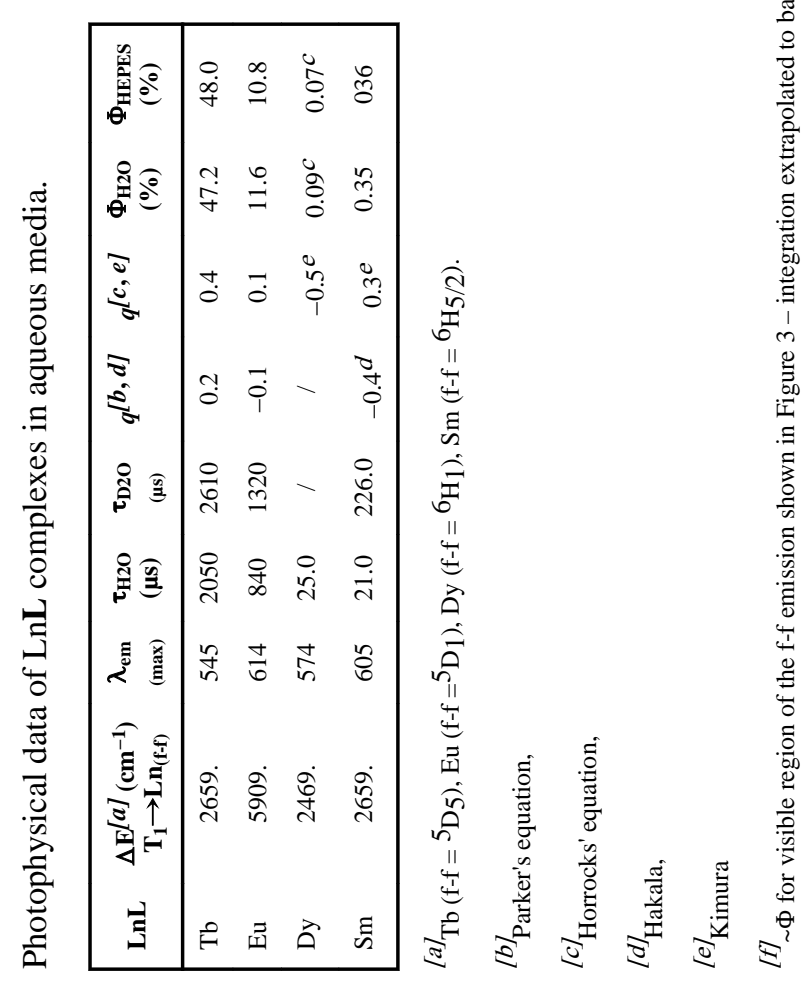

Angew Chem Int Ed Engl. Author manuscript; available in PMC 2013 March 05. 